Vol. 4, No. 2, Oktober 2020, hlm. 167-174

DOI: $10.37274 /$ rais.v4i02.333

\title{
Asalib At-Tarbiyah Al-Mustanbathah Min As-Surah Al-Ghosyiyah
}

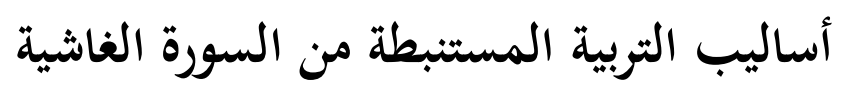

\author{
Jurais Mahali ${ }^{*}$, Abdul Hayyie Al-Kattani1 ${ }^{*}$ \\ ${ }^{1}$ Universitas Ibn Khaldun, Indonesia \\ *Juraismahali92@gmail.com \\ *Alkattani@gmail.com
}

$$
\begin{aligned}
& \text { الملخص } \\
& \text { القرآن الكريم هو دستور الأمة الإسلامية، المنزل من اللوح المحفوظ إلى سماء الدنيا ثم المنزل مع جبريل عليه }
\end{aligned}
$$

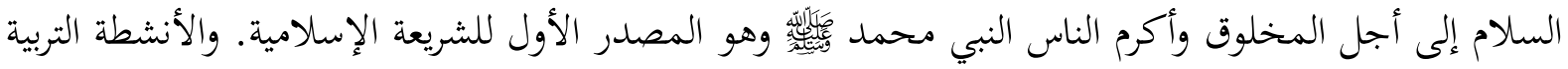

$$
\begin{aligned}
& \text { الإسلامية تحتاج إلى أساليب التربية من القرآن والسنة، وهذه الأساليب مهمة للغاية لأنه الأساليب الإلهية المنزل } \\
& \text { من عند الله جالاله وهو خالق البشر، العليم بما خلقه. واليوم عديد من المربي لم يستخدم أسلوب التربية الإسلامية } \\
& \text { بعدم معرفتهم بها، فيربي الجيل بغير منهاج التربية الإسلامية وأساليب التربية الإسلامية يولد منها جيل لا يعرف } \\
& \text { حق الله عليه. لهذا السبب قام الكاتب بإظهار تلك أساليب التربية الإلهية من السورة الغاشية. } \\
& \text { الكلمة الرئيسية: الأساليب، التربية، السورة الغاشية. }
\end{aligned}
$$

\begin{abstract}
The holly quran is the constitution of the IsImamic nation, the quran descent from the preserved tablet to the sky of the world, then the hostel with Gabriel Alaihi salam for the sake of the creature and the most honorable people of the prophet Muhammad shalallahu 'alaihi wasalam it is the first source of Islamic law legislation. And Islamic education activities need pedagogy methods from the Quran and Sunnah. These methods are very important because the divine methods were revealed from Allah, who is the Creator of mankind, the knower of what He created. Today, many educators did not use the Islamic education method, not knowing it, He raised a generation without the Islamic education curriculum and Islamic education methods, from which a generation is born that does not know God's right to it. For this reason, the author has demonstrated these methods of divine education from Surah Al-Ghasyah.
\end{abstract}

Keyword: Methods, Education, Surah Al-Ghasyah. 


\section{المقدمة}

الحمد لله رب العالمين مالك يوم الدين والصلاة والسلام على مربي الأمة وأصحابه ومن تبعهم بإحسان إلى يوم

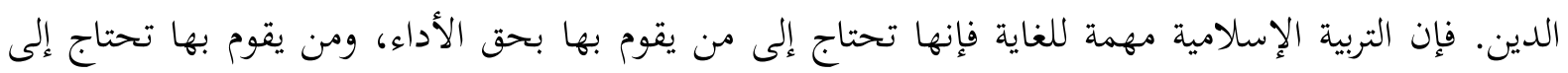

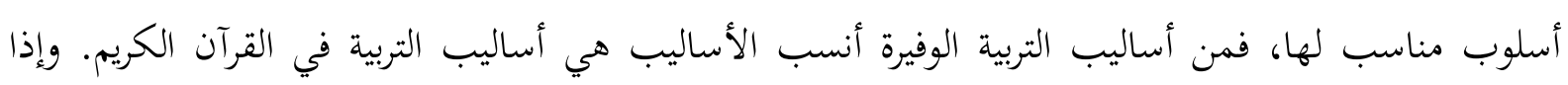
تناسب الأسلوب والمادة والمنهاج فستنتج أجيالا ربانيا يعرف حق الله على العبد، وتصبح المسلم ذو الشخصية

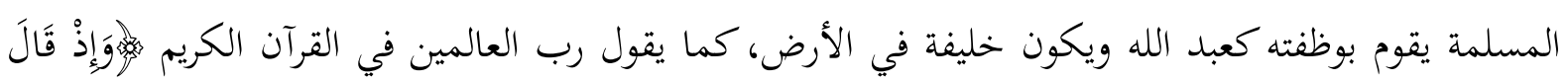

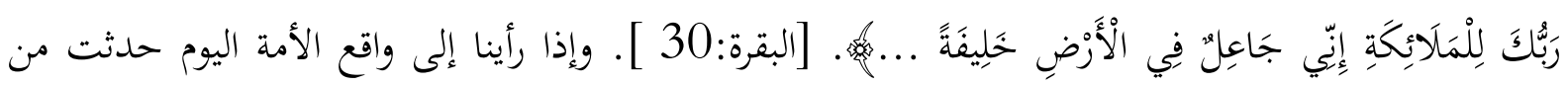
مخالفة الشريعة والتربية كارتكاب الجريمة والفواحش والقتل، ومن أسبابها الفشل في التربية والأساليب تؤثثر ذلك. حدثت الجريمة يفعلها طالب على مدرسته يغتصبها ثم يقتلها في سومطرى الجنوبية،

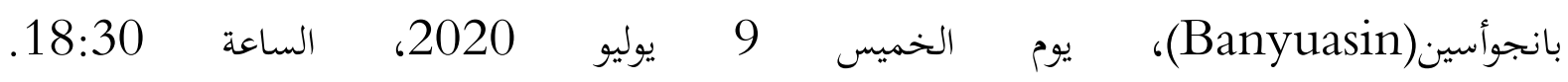
ضرب المدرس طالبه، حدثت في المدرسة الثانوية (news.okezone.com) فوروكيرتو(purwokerto) الجاوى الوسطى. (news.okezone.com) لتلك الحوادث يكون سببا من الأسباب لكتابة البحث عن أساليب التربية الصحيحة، حتى يتربى الطلاب بالتربية الإسلامية يصبح المسلم ذو الأخلاق الفاضلة.

فيكون أسئلة هذه الدراسة، ما هي أساليب التربية المستبطة من السورة الغاشية؟ ويكون الهدف هو اظهار أساليب التربية المستنبطة من السورة الغاشية.

\section{منهج البحث}

اعتمد الباحث لإنجز هذا البحث على المنهج الوصفي التحليلي، يكون البحث في استباط أساليب التربية من السورة الغاشية مستعينا بكتب التفاسير. 


\section{نتائج البحث}

أ. مفهوم التربية الإسلامية

معنى التربية في اللغة أنها تعود إلى الأصول الثلاثة هي: الأول: أنها من فعل تربّى - يتربى - تربية يعني

نشأ وترعرع وتعلم وتثقِف، "تربى الولد في بيئة صالحة". "اهتم الإسلام بتربية الأطفال"، هذا مذكور في المعجم فئم العربي بين يديك (عبد الرحمن، 1435). الثاني: من فعل ربا- يربو يعني زاد ونما، كما في قول الله ولوَوَمِنْ

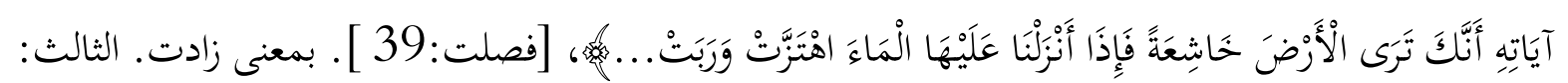
من فعل ربّ - يربٌُ بمعنى أصلح وساس ورعا، والربّ في الأصل من التربية، وهي تبليغ الشيء إلى كماله "شيئا

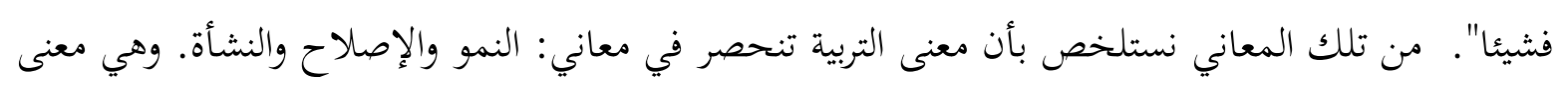
يكمل بعضها ببعض بما ينتج المفهوم الشامل للتربية. (عبد الله، 2011). وفي المعنى الواسع التربية هي التطوير الذاتي في كل جوانب الجسد، العقل والقلب (أحمد تفسير:

ثم الكلمة الإسلامية يعني النسبة إلى الإسلام فالتربية الإسلامية هي العملية المخططة في فطرة زمانية

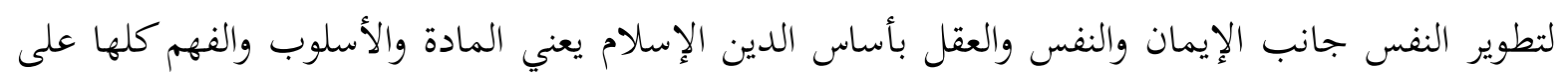
الأساس الإسلام،

$$
\begin{aligned}
& \text { ب. أساليب التربية المستنبطة من السورة الغاشية }
\end{aligned}
$$

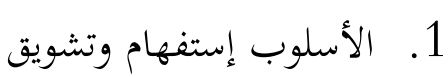

الإستفهام نوعان، الأول نوع يطلب به التصور أي ادراك المفرد، وتعيين الشيء وتحديده ويكون الجواب مع أدوات التصور بتعيين المسؤول عنه إذاكان الإستفهام حقيقيا، وهو قليل في القرآن الكريم. الثاني للتصديق أي يسأل به عن الحكم أو النسبة وتكون الإجابة بالنفي أو الإثبات ويشمل (هل) دائما (الهمزة) أحيانا (عبد الكريم: 2000)

$$
\text { نَاصِبَةُ (3) تَصْلَى نَارًا حَامِيَةَُهُ، [الغاشية: 1-3 ]. }
$$




\section{Mahali \& Al-Kattani}

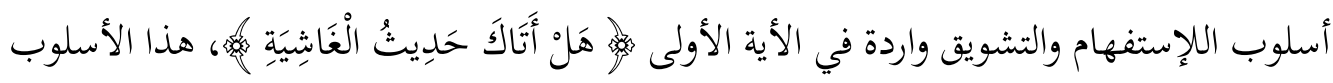

سيؤثر على السامعين بشرط أن يكون السؤال عن الأشياء التي عرفها المسؤول ولم يعلم الحقيقة أومواصفاتها الحقيقية، أو السؤل عن الأشياء التي لم يعرفها المسؤول فحيئذ تأثر المسؤول بإرادة قوية على معرفتها فهذا الشعور بالشويق، ثم أجاب السائل على السؤل حتى استجاب واقتنعت الإرادة

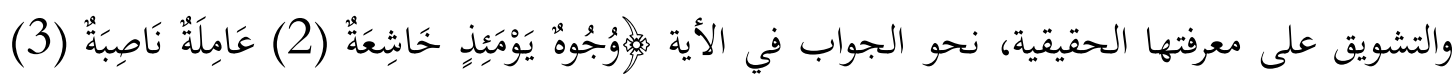

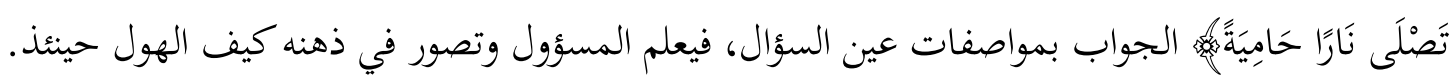
والله يعلم حق العلم بمشاعر الإنسان وكيف تثير تلك المشاعر فهذا دليل على عظمته سبحانه وتعالى، جدير على كل مربي الأمة استخدام هذا الأسلوب الإلهي القيم، فإنه تؤثر في نجاح التربية تأثيرا بالغا.

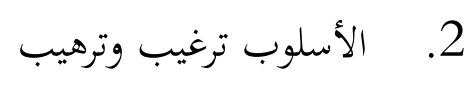

أسلوب الترغيب والترهيب هو أسلوب يتفق طبيعة الإنسان حيثما كان وفي أي مجتمع، لأن

المرئ إذا استشير شوقه إلى شيء ما، نما اهتماهه به، فسرعان ما يتحول هذا الشوق إلى النشاط يملأ

$$
\text { حياته.(أحمد: بدون سنة) }
$$

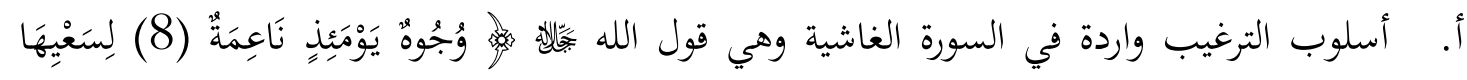

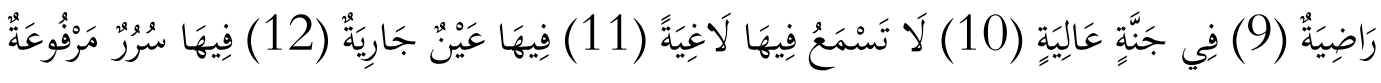

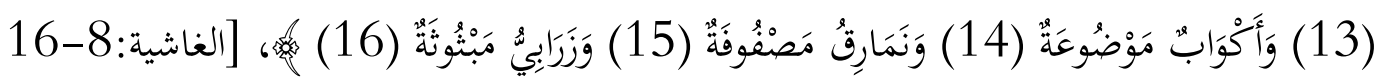

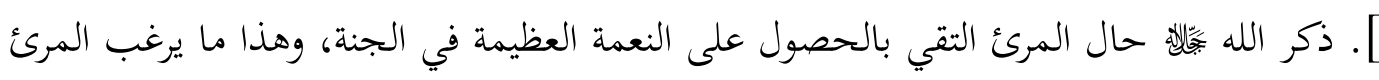

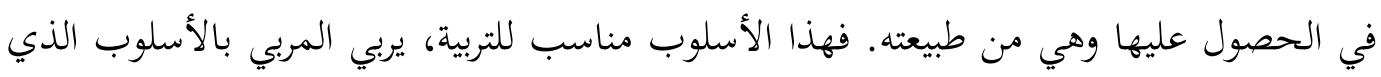

$$
\text { يناسب طبيعة الإنسان فيكون النسبة النجاح في التربية كبيرة. }
$$

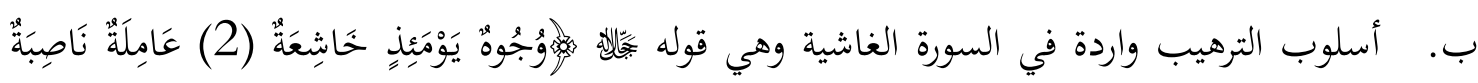

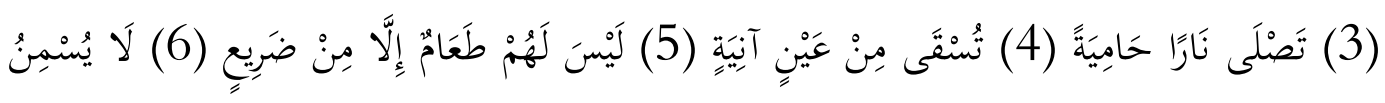




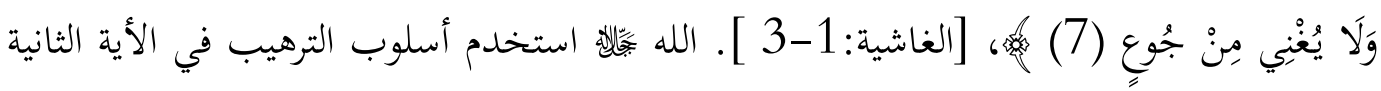
إلى الأية السابعة ليخاوف العبد من سوء العاقبة في الأخرة، بسبب عدم الطاعة في الأولى. فهذا

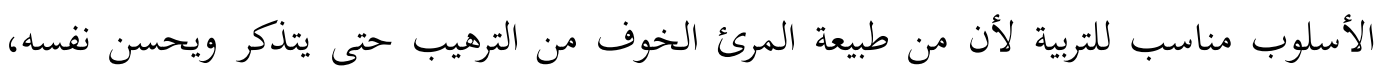

$$
\text { 3. فالأسلوب أمر التفكير والتأمل فرصة النجاح واسعة. }
$$

الأسلوب أمر التفكير والتأمل مهيم جدا لأنها تدفع إرادة التفكير لدي الطلبة وهو وارد في

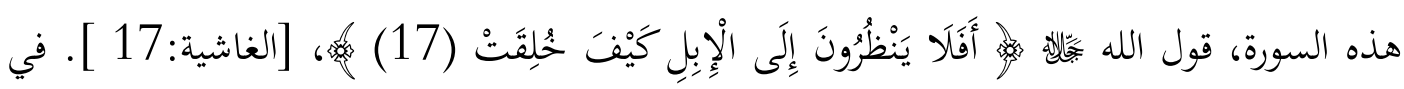
الأية أمر الله بالّ عباده بالنظر وليس مجرد النظر بل النظر مع التأمل والتفكير بحثا عن الحقيقة والعبرة المستورة عن عيون الناس ولا يدركها إلا المتأمل، ومن الحقيقة والعجائب في الجمل يقول الإمام ابن كثير في تفسيره (ابن كثير: 1999) "فإنها خلق عجيب، وتركيبها غريب، فإنها في غاية القوة والشدة، وهي مع ذلك يتحمل وتلين للحمل الثقيل، وتنقاد للقائد الضعيف، وتؤكل، ويتفع بوبرها، ويشرب لبنها. ونبهوا بذلك لأن العرب غالب دوابهم كانت الإبل". المربي الذي يربي يستطيع استعمال هذا الأسلوب لتنمية قدرة الطلاب على اكتشافات وإظهار الحقيقة المستورة من أعين

$$
\text { 4. }
$$

من أساليب التربية الإلهية هي أسلوب ضرب المثال الواردة في السورة الغاشية قوله تعالى موبر

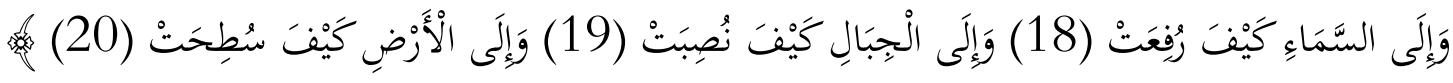
[الغاشية:18-20]. هذا الأسلوب مهم جدا، اتخذ الله الأمثلة ماشاء من مخلوقاته لتقريب فهم، وتصور العبد، حتى يصيل إلى الهدف فهو إظهار عظمة الله في قلوب العبد، وتعليمهم. قوله هورَ وَإلَى السَّمَاءٍ 


\section{Mahali \& Al-Kattani}

كَيْفَ رُرْعَتْ هُه تدل على عظمة الله أنه رفع السماء من غير عمد وهي من خلق الله العظيم ومن أكبر الخلق الذي يشهدها البشر و الجبل والأرض وهي التي بسط الله لمعاش الإنسان ومخلوقات أخرى.

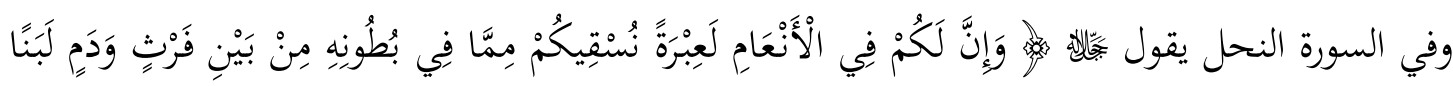

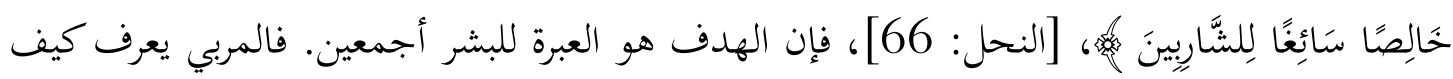
يتخذ مثالا تناسب الموضوع ومن الأفضل اتخاذ مثالا واقعيا والمعروفة لدى الطلبة، فإنه تؤثر في النجاح

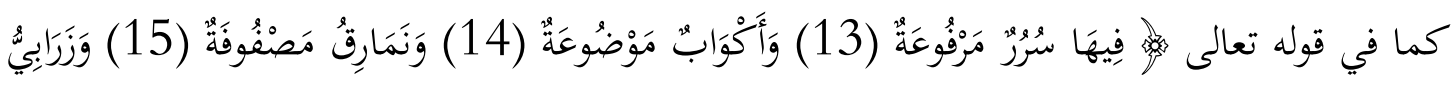

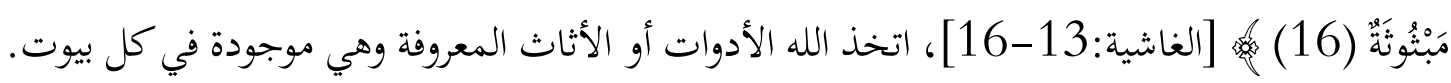

$$
\text { 5. - 5 الأسلوب تحفيز وتشجيع }
$$

التحفيز والتشجيع مهم للغاية فإنه تؤثر في نجاح التربية والدعوة، في السورة الغاشية قول الله

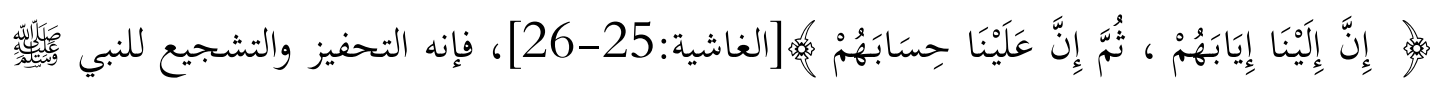

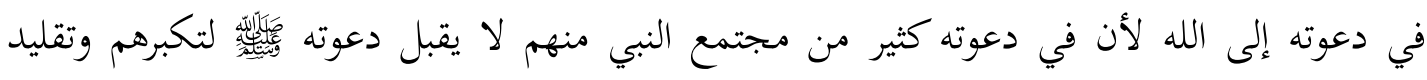

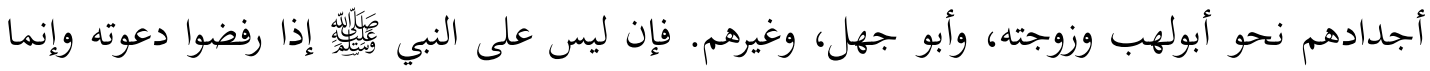

$$
\text { 6. الأسلوب إرشاد ابلهم ومأواهم. }
$$

الإرشاد هو الأمر الذي لو لم يحصل تبليغه حصل الضلال(نظام الدين:1416) إن أسلوب

الإرشاد من أساليب مهمة فإنها مطبقة في كثير من الأنشطة التعليمية والدعوية وهذا الأسلوب استخدم

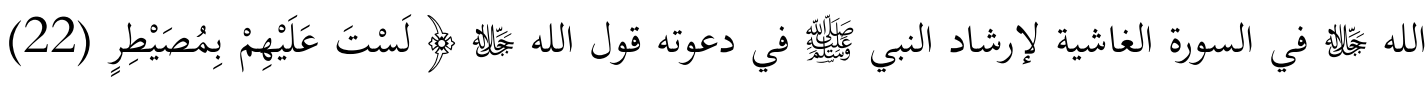

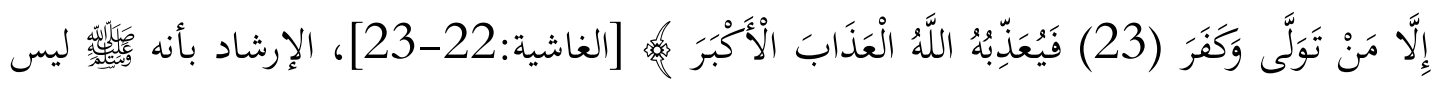

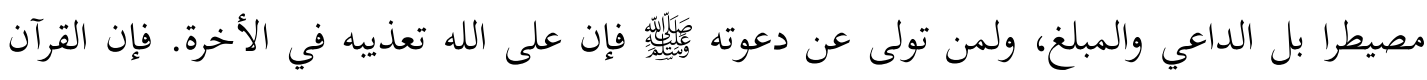

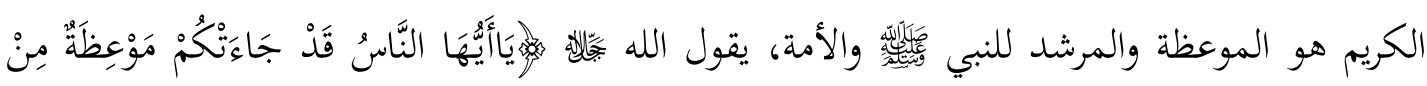




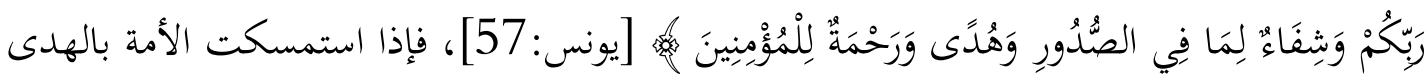
استقام طريقه وهو المرشد. ينبغي على كل المربي الإهتمام بهذا الأسلوب الإرشاد بأحسن الأداء، فكثير من عملية التربية يحدث انحراف والميل إلى غير هدف التربية فحيئذ يحتاج إلى الأسلوب

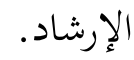

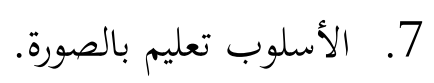

من أساليب التربية هو الأسلوب بالصورة الورقية والحقيقية أو الصورة الورقية، وأما اليوم في العصر

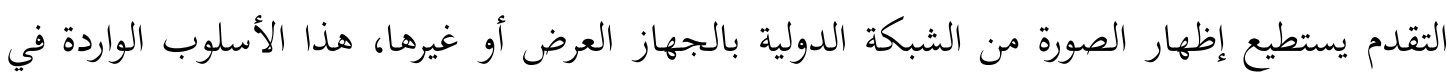
السورة الغاشية اتخذ الله ئاله الصور في هذه السورة وهي الصور الحقيقية الإبل، والسماء، والجبال،

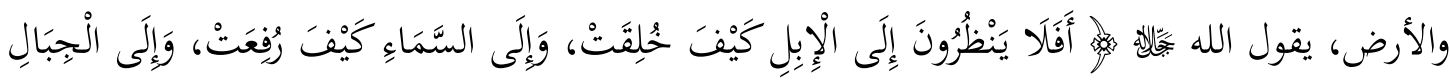

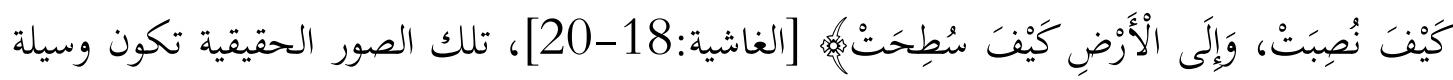
التعليم إظهار عظمة الله لمالّأ بأنه الخالق، العظيم، رب العالمين. فهذا الأسلوب من الأساليب الذي تعين على النجاح في التربية الإسلامية، عند الأنشطة التعليمية في الفصل يكون بالعرض، الورقية وغيرها، وأما خارج الصل بالصورة الحقيقية مباشرة.

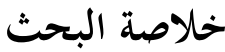

الأنشطة التربية تحتاج إلى تنوع الأساليب لأنها مهمة للغاية لسبب الطبيعة الطلاب أو الإنسان،

أنه لا يحب الدوام على أسلوب ما في وقت واحد فسوف يمل الطلبة، ولم يستطيع ادراك المعلومات حيئذ، وأما تنوع الأسلوب سيحب السامعين ويزيد قوة الفهم ويختلف المرئ من الأخر في قبول على المعلومة والله ماّله قد مثل لنا الأنشطة التربية في كل سورة من السور في القرآن الكريم بتنوع الأسلوب

$$
\text { 1. منها السورة الغاشية تتكون فيها سبعة أساليب وهي }
$$


Mahali \& Al-Kattani

$$
\begin{aligned}
& \text { 2. الأسلوب ترغيب وترهيب } \\
& \text { 3. الأسلوب أمر التفكير والتأمل } \\
& \text { 4. الأسلوب بضرب المثال } \\
& \text { 5. الأسلوب تحفيز وتشجيع } \\
& \text { 6. الأسلوب إرشاد } \\
& \text { الأسلوب تعليم بالصورة. }
\end{aligned}
$$

\section{المراجع}

ابن كثير، 1420هـ/ 1999م، تفسير القرآن العظيم، دار طيبة.

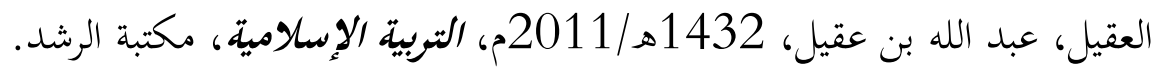
الفوزان، عبد الرحمن بن إبراهيم وغيره،1435هـ ، المعجم العببي بين يلديك، المملكة العربية السعودية. يوسف، عبد الكريم محمود، 1421هـ/2000م، أسلوب الإستغهام في القرآن الكريم، الشام، مكتبة

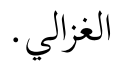
عيسى، أحمد بني، المدخل إلى الإدارة الإسلامية الحلديثة، اليازوري.

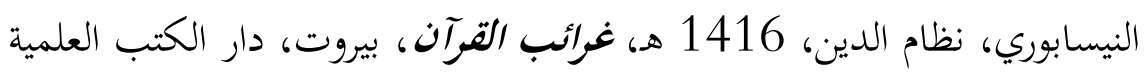

Tafsir, ahmad, 2015, Ilmu pendidikan Islam, bandung, rosdakarya.

https://news.okezone.com

https://m.liputan6.com 